\title{
Harberger-Laursen-Metzler Effect with Modified Becker-Mulligan Preference by Dynamic Optimization
}

\author{
Deng-Shan Wang, ${ }^{1}$ Miao Jin, ${ }^{2}$ and Zeng-Gang Guo ${ }^{3}$ \\ ${ }^{1}$ School of Science, Beijing Information Science and Technology University, Beijing 100192, China \\ ${ }^{2}$ Guanghua School of Management, Peking University, Beijing 100871, China \\ ${ }^{3}$ CEMA, Central University of Finance and Economics, Beijing 100081, China
}

Correspondence should be addressed to Deng-Shan Wang; wangdsh1980@163.com

Received 3 January 2016; Accepted 4 April 2016

Academic Editor: Taher S. Hassan

Copyright (C) 2016 Deng-Shan Wang et al. This is an open access article distributed under the Creative Commons Attribution License, which permits unrestricted use, distribution, and reproduction in any medium, provided the original work is properly cited.

\begin{abstract}
We investigate the effects of terms-of-trade shocks on the spending and current account where households with the modified Becker-Mulligan endogenous time preference maximize their utility over an infinite planning period. Our results show that, with the modified Becker-Mulligan preference, the effect of the deterioration in terms of trade on the current account depends on people's characters. However, with the second preference we have considered, the deterioration in terms of trade will result in a current account deficit, which is the same as Obstfeld (1982), where households with Uzawa endogenous time preference are considered; deterioration in terms of trade leads to a decline in the current account. These theoretical results are consistent with the empirical evidence by numerical simulations.
\end{abstract}

\section{Introduction}

There are many fluctuations in small open economies, since they tend to be easily disturbed by external shocks through international trade. The effects of deterioration in terms of trade faced by small open economies have caused much attention. Harberger [1] and Laursen and Metzler [2] put forward that a decrease in current income arising from an adverse terms-of-trade shock would lower both private savings and the current account balance. Meeting the conditions of Harberger-Laursen-Metzler effect (H-L-M effect), income effect caused by the terms-of-trade degradation will bring decreases of current income and total savings and then finally lead to the deterioration of the current account.

So far, the H-L-M effect has caused lots of academic discussions, and many researchers have gotten support for this effect or the contrary results, by establishing different models or modifying the parameters in the model, especially the time preference. Obstfeld [3] proposes a model to investigate the H-L-M effect, assuming that households maximize their utility over an infinite planning period. It is found that an economy specialized in production (means that the country is small and open) must experience a fall in aggregate spending and a current surplus as a result of an unanticipated, permanent worsening in its terms of trade. He provides a setting in which the current account deficit predicted by Harberger [1] and Laursen and Metzler [2] fails to materialize, where an endogenous Uzawa time preference is used. Following Uzawa [4], it is supposed that time preferences factor is a function of the utility of consumption level, and the consumer utility and the future patient degree changed inversely. Svensson and Razin [5] reexamine the issues on the basis of Obstfeld's propositions. They set up a two-period, two-good framework. A new discovery is that there are deteriorations in the current account and savings as a result of temporary deterioration in terms of trade, but this might go either way as a result of any permanent deterioration. After more than 20 years, Huang and Meng [6] investigate the effects of a permanent terms-of-trade change on a dynamic small open economy facing an imperfect world capital market as studied in Obstfeld [3] under the assumption that households' subjective discount rate is a decreasing function of instantaneous 
utility. They show that an unanticipated permanent termsof-trade deterioration leads to an increase in aggregate expenditure and a current account deficit, which is in stark contrast to those obtained in Obstfeld [3].

Sen and Turnovsky [7] use fixed time preferences in the indefinite model to discuss the H-L-M effect. They consider the choice between leisure (labor) and capital accumulation. In their model, worsening terms of trade would lead to the current account deficit or do not depend on people's investment behavior. Based on the habit fixed model, Mansoorian [8] also considers the demonstration in the discussions of the indefinite model. In the model, the changes of people habits depend on the past consumption. If time preferences change as people's consumption slowly changes, the deteriorating terms of trade will gradually reduce savings and eventually lead to the current account deficit. More recently, Angyridis and Mansoorian [9] investigate the influences of termsof-trade deterioration on the current account when the representative agent has Marshallian preference. With this preference, the rate of time preference is a decreasing function of savings and the permanent income of the representative agent is reduced by the terms-of-trade deterioration. As savings fall, the country experiences a current account deficit. Various evaluations of the model imply that the H-L-M effect is applied in an infinite horizon model with an endogenous rate of time preference, with standard functional forms and reasonable parameter values.

Becker and Mulligan [10] propose a time preference that is not a by-product of other choices. The presupposition is that consumers often make efforts and carry out activities in order to influence the discount on future utilities. According to the viewpoint, the resources are spent on imagining future pleasures, which is termed as "future oriented capital," determining the rate of a time preference. Thus, Becker and Mulligan determine the time preference rate by relating it to resources spent on imagining future pleasures, where the larger the resources are spent the more patient the individual is. Such resources may be spent on schooling, newspapers, membership in a Christmas Club, and so on. In what follows, for simplicity we call this Becker-Mulligan endogenous time preference to be B-M preference.

Recently, there are a vast and ever-growing number of studies on the B-M preference. For example, Gong and Zou [11] discuss the effects of government expenditure, income tax rate, and consumption tax rate on the steady-state capital stock, consumption level, in the Ramsey model with B-M preference, and find that, with the increasing of the government expenditure, the steady-state capital stock and the spending on imaging the future will be decrease, but the effect on the consumption level is ambiguous. Recently, Gong [12] investigates the effects of monetary growth in an infinitely lived, representative agent model with B-M preference. He finds that an increase in the inflation rate reduces the resources spent on imagining the future, which increases the rate of time preference and decreases the steady-state value of capital stock.

This paper studies the H-L-M effect with modified B-M preference which has been the academic focus for more than a half century. We present the model based on the modified
B-M preference in Section 2. In the model, the representative consumer strengthens his expectation of future consumption with certain endowment, and the model has the utility maximization function and restrictive conditions about capital increase. Using the Pontryagin Maximum Principle [13], we get the optimality conditions when the objective function model is maximized and the conditions which guarantee that the economy becomes stable. Section 3 studies the saddle point stability of the economy system and points out the existence and inexistence of the H-L-M effect which depend on people's characters. The empirical evidence is explored by numerical simulations in Section 4. We conclude this paper in the final section.

\section{The Model}

Consider an open and small economy consisting of identical households, each maximizing its utility over an infinite lifetime. Assume that the instantaneous utility function $U$ is composed of two goods: one is imported from abroad, $c^{f}$, and the other is available at home, $c^{h}$, in fixed supply. Households may save by accumulating an internationally traded bond, $b$, which is assumed, without loss of generality, to be indexed to the foreign good.

2.1. Assumptions. The instantaneous utility function $U$ of the representative household is taken to be nonnegative, strictly increasing in both its arguments, strictly concave, and twice continuously differentiable. To avoid noninterior solutions to the household's lifetime consumption problem, we assume that

$$
\lim _{c_{t}^{f} \rightarrow 0} \frac{\partial U}{\partial c_{t}^{f}}=\lim _{c_{t}^{h} \rightarrow 0} \frac{\partial U}{\partial c_{t}^{h}}=\infty .
$$

The household's objective is to maximize the discounted sum of future instantaneous utility:

$$
\int_{0}^{\infty} U\left(c^{f}, c^{h}\right) e^{-\Delta_{t}} d t
$$

where

$$
\Delta_{t}=\int_{0}^{t} \rho(s(v)) d v
$$

Following Becker and Mulligan [10], assume that people have the option to increase their appreciation of the future. This effort can be modeled by allowing the consumer to make future pleasures less remote by spending resources on imagination, which is denoted as $s$. Suppose that the time preference is a function of the spending resources $s$, mathematically $\rho(s)$, and we make two assumptions as follows:

Case 1:

$$
\begin{gathered}
\rho(s)>0, \\
\rho^{\prime}(s)<0, \\
\rho^{\prime \prime}(s)<0 .
\end{gathered}
$$


Case 2:

$$
\begin{gathered}
\rho(s)>0, \\
\rho^{\prime}(s)>0, \\
\rho^{\prime \prime}(s)>0,
\end{gathered}
$$

for all $s \geq 0 .{ }^{1}$ With the assumption in (4a), the time preference in maximization problem (3) is called the modified B-M preference. The assumption in (4b) is another case we have considered.

From (4a), we know that, with the increasing of the resources spent on imagination, the propinquity of future pleasures will increase, and thus $\rho(s)$ is decreasing. The concavity assumption $\rho^{\prime \prime}(s)<0$ requires that the resources spent on imagining future utilities become increasingly more effective in decreasing their remoteness.

At each instant, the representative family is bound by a flow constraint linking any divergence between its income and its expenditure to its accumulation of claims on future units of the foreign good. Letting $b=b(t)$ denote bond holdings at time $t$, letting $p$ be the price of foreign goods in terms of domestic goods, letting $y$ be the family's (fixed) endowment of the home good, and letting $r$ be the international rate of interest, we can write this budget constraint as

$$
\dot{b}=\frac{y}{p}-c^{f}-\frac{c^{h}}{p}+r b-\frac{s}{p},
$$

which implies that, for the economy as a whole, the capital account deficit must be equal to the excess of income over expenditure and resources spent on imagination.

The household is also bound by a second constraint on its program of saving and spending. The discounted integral of lifetime expenditure (measured in domestic goods) and resources spent on imagination must be not greater than the capitalized value of lifetime output plus initial bond holdings; that is,

$$
\frac{y}{r}+p b_{0} \geq \int_{0}^{\infty} e^{-r}\left[p c^{f}+c^{h}+s\right] d t .
$$

The importance of this constraint can be appreciated by contrasting the present infinite horizon planning problem with a finite-horizon problem whose planning period ends at time $T$. In the latter setting, the family's budget constraint clearly implies that $b(T)$ is nonnegative, and for any lifetime, borrowing must be repaid before death. But an infinitely lived family facing a perfect capital market may borrow and consume arbitrarily large amounts while it is always meeting its interest payments through further borrowing. Its lifetime utility is unbounded; that is, no optimal program exists unless such a condition is imposed.

To rule out this "paradox of borrowing," we impose the feasibility constraint that, at each moment, the family's capitalized future output must exceed its indebtedness:

$$
\frac{y}{r}+p b \geq 0
$$

The household's problem is to choose paths for consumptions on $c^{f}, c^{h}$, and $s$ to

$$
\begin{array}{ll}
\text { maximize } & \int_{0}^{\infty} U\left(c^{f}, c^{h}\right) e^{-\Delta_{t}} d t \\
\text { subject to } & \text { (i) } \Delta_{t}=\int_{0}^{t} \rho(s(v)) d v, \\
& \text { (ii) } \dot{b}=\frac{y}{p}-c^{f}-\frac{c^{h}}{p}+r b-\frac{s}{p}, \\
& \text { (iii) } c^{f}, c^{h} \geq 0, \\
\text { (iv) } \frac{y}{r}+p b \geq 0,
\end{array}
$$

given an initial stock $b_{0}$ of net claims on foreigners. The number of households is for convenience taken to be 1 , so that the consumption and saving paths chosen by the representative household may be identified with those of the economy as a whole.

2.2. Two Simplifications. Two simplifications will facilitate our derivation of the necessary conditions for a solution to problem (8), just as what Obstfeld [3] has used. In order to maximize the lifetime welfare, at each moment the household must maximize its instantaneous utility, given relative prices and its chosen level of expenditure on consumption goods in general. The first simplification is to replace the utility function with the indirect utility function as

$$
V(p, z) \equiv \sup \left\{U\left(c^{f}, c^{h}\right) \mid p c^{f}+c^{h}=z\right\},
$$

which both reduces the dimensionality of our problem and allows us to focus on a variable of primary interest, expenditure measured in terms of the domestic good $z$.

The second simplification is achieved by changing variables in the maximization problem from $t$ to $\Delta_{t}$, using the fact that

$$
d \Delta_{t}=\rho(s) d t
$$

which reduces the household's problem to that of choosing a path for $z$ and $s$ to

$$
\begin{aligned}
& \text { maximize } \int_{0}^{\infty} \frac{V(p, z)}{\rho(s)} e^{-\Delta_{t}} d \Delta_{t}, \\
& \text { subject to } \frac{d b}{d \Delta_{t}}=\frac{(y-z-s) / p+r b}{\rho(s)},
\end{aligned}
$$

and the given initial bond holdings $b_{0}$.

2.3. Solutions of the Model. Necessary conditions for a solution to such a maximization problem are readily derived using the Pontryagin Maximum Principle. ${ }^{3}$ To apply this principle, we introduce the costate variable $\lambda=\lambda_{\Delta}$, which may be interpreted as the imputed value or shadow price of saving, measured in utility terms. According to the Maximum 
Principle, an optimal program must maximize the following Hamiltonian for each $\lambda$ :

$$
H(b, z, s, \lambda)=\frac{V(p, z)+\lambda[(y-z-s) / p+r b]}{\rho(s)},
$$

with respect to $b, z$, and $s$.

The solutions to the first-order conditions $\partial H / \partial z=0$ and $\partial H / \partial s=0$ are

$$
\begin{aligned}
& \lambda=p V_{z}, \\
& \lambda=\frac{-p V}{y-z-s+\rho / \rho^{\prime}(s)+r p b} .
\end{aligned}
$$

The Euler equation reversing initial change of variables $\left(d \Delta_{t}=\rho(s) d t\right)$ is

$$
\dot{\lambda}=\lambda(\rho(s)-r),
$$

which denotes that the marginal rate of time preference must at each instant equal the rate of return on bonds plus "capital gains," that is, $\dot{\lambda} / \lambda$. Moreover, from the previous simplification, the feasibility budget condition is

$$
\dot{b}=\frac{(y-z-s)}{p}+r b .
$$

While the four equations (14)-(17) are necessarily satisfied by an optimal program, they are not in themselves sufficient to guarantee optimality. The stock of bonds inherited from the past is predetermined at time $t=0$ and this fact provides an initial condition for the differential equation system defined by the four equations (14)-(17). But an initial value of shadow price $\lambda$ is also required, and unless this shadow price is chosen correctly, the path will be suboptimal. The problem is again due to our assumption that the planning unit has an infinite lifetime. If this lifetime instead ends at time $T$, the terminal condition $b(T)=0$ would enable us to solve backward for $\lambda_{0}$. But in the present context, no such restriction is available.

2.4. Stationary Conditions. It is natural to consider the steady state $(\bar{z}, \bar{b}, \bar{s})$ of the economy. Firstly, the condition

$$
\dot{\lambda}=\lambda(\rho(s)-r)=0
$$

guarantees that the marginal rate of time preference equals the rate of interest, and the condition

$$
\dot{b}=\frac{(y-z-s)}{p}+r b=0
$$

gives the external balance. The reason for doing so is that the paths which converge to the steady state satisfy the sufficiency condition for optimal problem

$$
\lim _{\Delta \rightarrow \infty}\left[\frac{y}{r p}+b_{\Delta}\right] e^{-\Delta} \lambda_{\Delta}=0
$$

and so are optimal. In the next section, we show that there exists a unique convergent path, which will guarantee that the economy's response to a permanent change in the parameters that it faces is uniquely determined.

\section{The H-L-M Effect with Modified B-M Preference}

We are interested in the situation that there is a steady state and an optimal path moving towards to it. Just as shown above, the optimal path must be in accordance with (14)-(17), and the steady state will be determined by (18) and (19).

3.1. The Steady State. Firstly, transform the differential equation (16), an equation of shadow price $\lambda$, into the equation of expenditure $z$. From (14), we know

$$
\dot{\lambda}=p V_{z z} \dot{z}
$$

Putting (14) and (21) into (16), we have

$$
\dot{z}=\frac{V_{z}}{V_{z z}}(\rho(s)-r) .
$$

From (14) and (15), we get

$$
s-\frac{\rho(s)}{\rho^{\prime}(s)}=y-z+\frac{V}{V_{z}}+r p b,
$$

from which and the implicit function theorem we can represent $s$ as functions of $b$ and $z$; that is,

$$
s=s(z, b) .
$$

Thus the steady state $(\bar{z}, \bar{b}, \bar{s})$ of the economy with $\bar{s}=$ $\bar{s}(\bar{z}, \bar{b})$ reached when $\dot{z}=\dot{b}=0$ is characterized by

$$
\begin{aligned}
\frac{V_{z}}{V_{z z}}(\rho(\bar{s})-r) & =0, \\
\frac{(y-\bar{z}-\bar{s}(\bar{z}, \bar{b}))}{p}+r \bar{b} & =0 .
\end{aligned}
$$

The linearized system associated with the dynamic system (19) and (22) around the steady state is

$$
\left(\begin{array}{l}
\dot{z} \\
\dot{b}
\end{array}\right)=\left(\begin{array}{cc}
\frac{V_{z}}{V_{z z} \rho^{\prime}(\bar{s}) \bar{s}_{z}} & \frac{V_{z}}{V_{z z}} \rho^{\prime}(\bar{s}) \bar{s}_{b} \\
\frac{\left(-1-\bar{s}_{z}\right)}{p} & \frac{-\bar{s}_{b}}{p}+r
\end{array}\right)\left(\begin{array}{l}
z-\bar{z} \\
b-\bar{b}
\end{array}\right) .
$$

The determinate of the coefficient matrix of the above linear system is given by

$$
\begin{gathered}
\operatorname{det}\left(\begin{array}{cc}
\frac{V_{z}}{V_{z z}} \rho^{\prime}(\bar{s}) \bar{s}_{z} & \frac{V_{z}}{V_{z z}} \rho^{\prime}(\bar{s}) \bar{s}_{b} \\
\frac{\left(-1-\bar{s}_{z}\right)}{p} & \frac{-\bar{s}_{b}}{p}+r
\end{array}\right) \\
=\frac{V_{z}}{V_{z z}} \rho^{\prime}(\bar{s})\left(r \bar{s}_{z}+\frac{\bar{s}_{b}}{p}\right) .
\end{gathered}
$$


From (23), we have

$$
\begin{aligned}
& s_{z}=-\frac{V V_{z z}}{V_{z}^{2}} \cdot \frac{\rho^{\prime 2}(s)}{\rho \rho^{\prime \prime}(s)}, \\
& s_{b}=r p \cdot \frac{\rho^{\prime 2}(s)}{\rho \rho^{\prime \prime}(s)} .
\end{aligned}
$$

In the next two subsections, we analyze the dynamic system (19) and (22) above near the steady state and investigate the existence of the H-L-M effect.

3.2. The H-L-M Effect in Case 1. Under the assumption in Case 1, we have

$$
\begin{aligned}
& s_{z}=-\frac{V V_{z z}}{V_{z}^{2}} \cdot \frac{\rho^{\prime 2}(s)}{\rho \rho^{\prime \prime}(s)}<0, \\
& s_{b}=r p \cdot \frac{\rho^{\prime 2}(s)}{\rho \rho^{\prime \prime}(s)}<0 ;
\end{aligned}
$$

thus the determinant of the coefficient matrix of (26), that is, (27), is negative. So the dynamic system has one negative and one positive characteristic root, which is crucial for stability. The dynamic system has a perfect foresight saddle point path near the steady state. The phase diagram analysis is done to show the changes of current account and expenditure in response to terms-of-trade shocks. Firstly, consider the $\dot{z}=0$ locus. Any point on this locus must satisfy $\rho(s(z, b))=r$, so differentiating both sides with respect to $z$, we have

$$
\rho^{\prime}(s)\left(s_{z}+s_{b} \cdot \frac{d b}{d z}\right)=0 .
$$

Hence we have

$$
\frac{d b}{d z}=-\frac{s_{z}}{s_{b}}<0,
$$

which shows that $\dot{z}=0$ locus is downward in the diagram. For the $\dot{b}=0$ locus, in the same way, we have

$$
\frac{d b}{d z}=\frac{s_{z}+1}{p r-s_{b}},
$$

whose slope depends on the sign of the numerator. In what follows, the sign of $d b / d z$ is considered in two cases.

Case 1. (a) If $s_{z}+1>0$, we have $d b / d z>0$ and the $\dot{b}=0$ curve is upward. When doing the long-run equilibrium analysis, $\dot{b}=0$ shows the $p r b+y=z+s(z, b)$. Thus when the price $p$ increases, this curve must move downward. Figure 1 displays the dynamic behaviors of the system described by (19) and (22) in response to the increase of price $p$. It is shown that when facing with the deterioration in terms of trade (i.e., the price $p$ increases), the current account of the small open economy will decrease and the expenditure will increase to get to a new saddle point path. This supports the H-L-M presumption of a current account deficit when deterioration of terms-of-trade occurs.

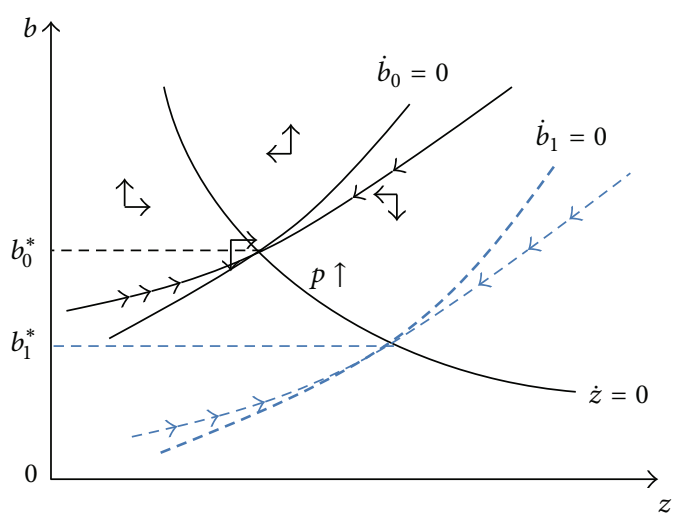

FIgURE 1: The phase diagram and the effect of a permanent termsof-trade deterioration for Case 1(a).

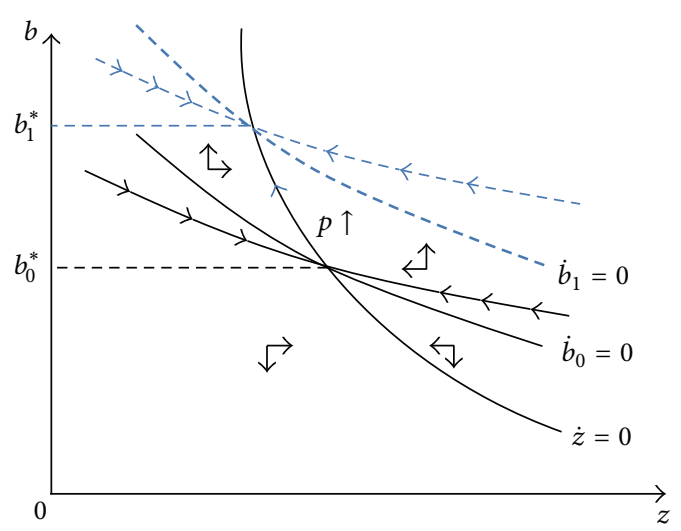

Figure 2: The phase diagram and the effect of a permanent termsof-trade deterioration for Case 1(b).

(b) If $s_{z}+1<0$, we have $d b / d z<0$. In this case, one should firstly compare the slope of the curves $\dot{b}=0$ and $\dot{z}=0$, since

$$
\frac{s_{z}+1}{p r-s_{b}}-\left(-\frac{s_{z}}{s_{b}}\right)=\frac{s_{b}+p r s_{z}}{\left(p r-s_{b}\right) s_{b}}>0 .
$$

The $\dot{b}=0$ curve is flatter than the $\dot{z}=0$ curve. Figure 2 displays the dynamic behaviors of the system described by (19) and (22) in response to the increase of price $p$. It is observed that the deterioration in terms of trade leads to the increase of the current account and decrease of the expenditure, which is a result contrary to the $\mathrm{H}-\mathrm{L}-\mathrm{M}$ presumption of a current account deficit when worsening of terms-of-trade occurs.

3.3. The H-L-M Effect in Case 2. Under the assumption in Case 2, we have

$$
\begin{aligned}
& s_{z}=-\frac{V V_{z z}}{V_{z}^{2}} \cdot \frac{\rho^{\prime 2}(s)}{\rho \rho^{\prime \prime}(s)}>0, \\
& s_{b}=r p \cdot \frac{\rho^{\prime 2}(s)}{\rho \rho^{\prime \prime}(s)}>0,
\end{aligned}
$$




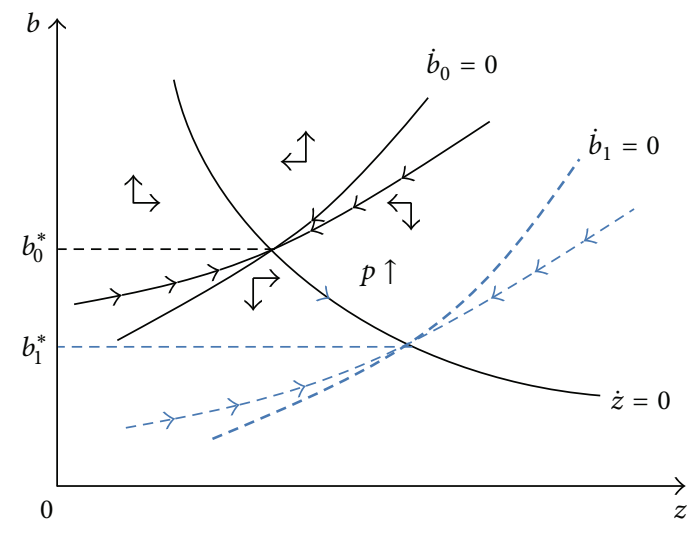

FIGURE 3: The phase diagram and the effect of a permanent termsof-trade deterioration for Case 2(a).

so the determinant of the coefficient matrix of (26), that is, (27), is also negative. So the dynamic system has one negative and one positive characteristic root, which has a perfect foresight saddle point path near the steady state. In the following, the phase diagram analysis is done to show the changes of current account and expenditure in response to terms-of-trade shocks. The $\dot{z}=0$ locus can be easily drawn as what we have done in Section 3.2. Since

$$
\frac{d b}{d z}=\frac{s_{z}+1}{p r-s_{b}},
$$

the sign of $\mathrm{pr}-s_{b}$ is key to know the direction of the curve $\dot{b}=0$. We should also consider two cases to determine the sign of $d b / d z$.

Case 2. (a) When $p r>s_{b}$, that is, $\rho^{\prime}(s)^{2} /\left(\rho(s) \cdot \rho(s)^{\prime \prime}\right)<1$, we have

$$
\frac{d b}{d z}=\frac{s_{z}+1}{p r-s_{b}}>0 .
$$

So the $\dot{b}=0$ curve is upward. As done in Section 3.2, when the price $p$ increases, the $\dot{b}=0$ curve moves downward. Figure 3 displays the phase diagram and effect of a permanent termsof-trade deterioration. It is shown that when facing with the deterioration in terms of trade, the current account decreases and the expenditure increases to get to a new saddle point path, which supports the H-L-M presumption of a current account deficit when deterioration of terms-of-trade occurs. have

(b) When $p r<s_{b}$, that is, $\rho^{\prime}(s)^{2} /\left(\rho(s) \cdot \rho(s)^{\prime \prime}\right)>1$, we

$$
\frac{d b}{d z}=\frac{s_{z}+1}{p r-s_{b}}<0 .
$$

So the $\dot{b}=0$ curve is downward. We should compare the slope of this two curves to determine their location in the diagram. Since

$$
\frac{s_{z}+1}{p r-s_{b}}-\left(-\frac{s_{z}}{s_{b}}\right)=\frac{s_{b}+p r s_{z}}{\left(p r-s_{b}\right) s_{b}}<0,
$$

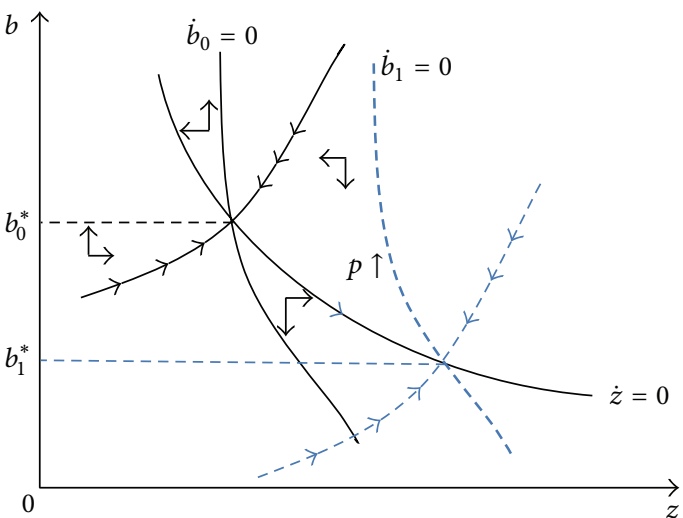

FIgURE 4: The phase diagram and the effect of a permanent termsof-trade deterioration for Case 2(b).

the $\dot{b}=0$ curve must be steeper than $\dot{z}=0$. Figure 4 also displays the phase diagram and effect of a permanent termsof-trade deterioration. We see that when facing with the deterioration in terms of trade, the current account decreases and the expenditure increases to get to a new saddle point path, which supports the H-L-M presumption.

\section{Empirical Evidence by Numerical Simulations}

To illustrate the results above, the analytical model is simulated numerically. As is known, this model poses a twopoint boundary value problem in a continuous setting and the deterioration in terms of trade is permanent; we refer to the simulation method used by Trimborn et al. [14].

For the numerical implication, the instantaneous utility function is taken to be Cobb-Douglas, so that the import content of consumption is independent of relative price, which is the same as Serven [15] and the form is

$$
U\left(c^{f}, c^{h}\right)=\frac{\left(\left(c^{f}\right)^{\theta}+\left(c^{h}\right)^{1-\theta}\right)^{1-\delta}}{1-\delta},
$$

where the parameter $\theta$ satisfies $0<\theta<1$.

Our choice of preference parameters is standard, the same as Eicher et al. [16]. The time preference function is set as quadratic with a parameter $\rho_{0}$; that is,

$$
\rho(s)=\rho_{0} s^{2}
$$

The world real interest rate is $r=0.06$ and the constant income is $y=0.5$. The terms of trade is 0.95 initially and rises to 1 , as shown in Table 1 . Thus the transitional paths begin at the initial steady state and then come to the new steady state after the terms of trade deteriorates.

With the parameterization in Table 1, Figure 5 presents the simulated trajectories of bond holdings, consumptions, and resources on the imagination following a permanent unanticipated increase in the price. 
TABLE 1: The data in empirical analysis.

\begin{tabular}{lc}
\hline Preference parameters & $\theta=0.5, \delta=2.5, \rho_{0}=0.01$ \\
Constant income & $y=0.5$ \\
World interest rate & $r=0.06$ \\
Terms of trade & $p_{0}=0.95, p_{1}=1$ \\
\hline
\end{tabular}

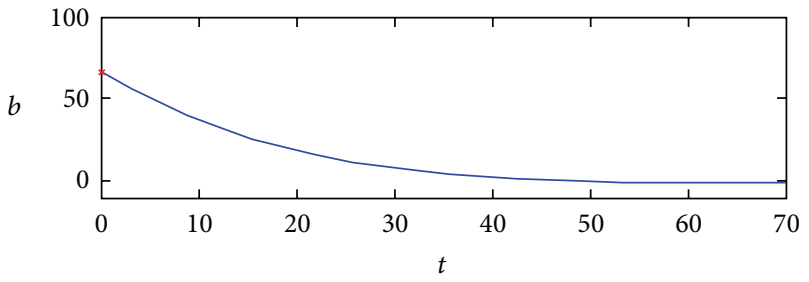

(a)

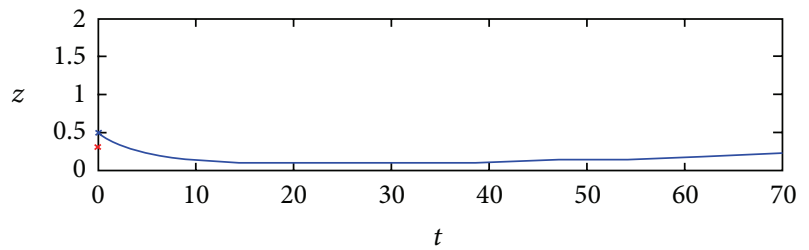

(b)

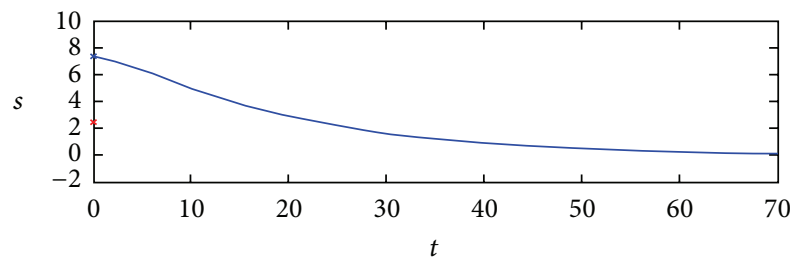

(c)

Figure 5: Time evolutions of bond holdings, consumptions, and resources.

It is shown in Figure 5 that starting from the steady-state equilibrium at time $t=0$, both consumption and resources spent on imagination jump to a higher level, from the red point to the blue point, in the short run. Bond holdings decrease in the short run and in the long run, which means that the current account is deficit and the result is the same as the outcome predicted by Laursen and Metzler [2] and Obstfeld [3], which is consistent with theoretical results in Section 3, where the H-L-M effect exists.

\section{Conclusion}

Obstfeld [3] finds that, in a context of explicit, intertemporal optimization, the well-known H-L-M relationship predicts a decline in saving and thus a current deficit is invalid. Deterioration in the terms of trade, in his paper, leads to a current surplus as households acquire interest-bearing claims on foreigners in order to restore their steady-state utility to its original level. He assumes that people have Uzawa preference, which holds the point that time preferences factor is a function of the utility of consumption level. However, according to Marshall [17], agents derive direct utility from the act of savings. It is demonstrated by Angyridis and Mansoorian [9] that, with this preference, a terms-of-trade deterioration, by lowering the permanent income of the representative agent, reduces savings and leads to a current account deficit. This supports the H-L-M effect.

Becker and Mulligan [10] believe that consumers often make efforts and carry out activities to influence the discount on future utilities. According to their viewpoint, the resource spent on imagining future pleasures, which is called $s$, is to increase their appreciation of the future. By modifying this time preference, we study in this paper the H-L-M effect which has been the academic discussion for a half century.

We have studied the H-L-M effect on an open economy peopled by infinitely lived, utility-maximizing families, and it is found that whether the H-L-M effect exists depends on people's characters, such as sagacity and far-sight. The validity of the H-L-M prediction depends in general on the economy's intertemporal utility forms and its time preferences. We have analyzed some possible cases and have focused on resources on imagination that are freely chosen, but it is clearly desirable to extend our analysis to more general resources changing paths, for example, to the expenditure. In the future work, we will develop a two-country world economy with modified Becker-Mulligan endogenous time preference to investigate the macroeconomic dynamics and H-L-M effect [18]. Moreover, in order to associate with the recent empirical evidence, we will incorporate investment behavior explicitly in the model. The inclusion of investment is important because the current account should be the difference between saving and investment, and hence investment should play an important role in explaining the current account adjustment. There are numerous studies that argue that the current account fluctuations are largely driven by investment rather than by saving $[19,20]$. The recent empirical evidence also indicates that capital goods in trade flows actually represent the leading import item for many countries [21, 22]. Thus the empirical studies [23-25] provide a way for us to improve the theoretical model [26].

\section{Competing Interests}

The authors declare that there are no competing interests regarding the publication of this paper.

\section{Acknowledgments}

This work is supported by Training Program for the Major Fundamental Research of Central University of Finance and Economics (Grant no. 14ZZD001), National Natural Science Foundation of China under Grant nos. 11271362, 11201501, 11375030, and 11571389, Beijing Nova Program no. Z131109000413029, and Beijing Finance Funds of Natural Science Program for Excellent Talents no. $2014000026833 Z$ K19.

\section{Endnotes}

1. This may be different to common sense of economy but ensure our calculation in further discussion, with the affirmation that $\rho^{\prime \prime \prime}(s)>0$. 
2. We can easily affirm that $\partial V / \partial z>0$ and $\partial^{2} V / \partial z^{2}<0$, which means that the household's utility will increase if the expenditure grows up, but its effect will decrease. And $\partial^{2} V / \partial z \partial p>0$ can be deduced by the concavity of $V$ and will help us calculate the model in Section 2.3.

3. See Arrow and Kurz [27] or Kamien and Schwartz [13], in their book Dynamic Optimization, where the Pontryagin Maximum Principle is referred to. Suppose that the problem is to maximize $\int_{t_{0}}^{t_{1}} f(t, x(t), u(t)) d t$, subject to $\dot{x}(t)=g(t, x(t), u(t))$, given $x\left(t_{0}\right)$. Then define Hamilton function:

$$
H(t, x, u, \lambda)=f(t, x, u)+\lambda g(t, x, u),
$$

where $\lambda$ is a Hamilton multiplier. The solutions to the problem must satisfy the necessary conditions as

$$
\begin{aligned}
& \frac{\partial H}{\partial u}=\frac{\partial f}{\partial u}+\lambda \frac{\partial g}{\partial u}=0, \\
& \frac{d \lambda}{d t}=-\frac{\partial H}{\partial x}=-\frac{\partial f}{\partial x}-\lambda \frac{\partial g}{\partial x} .
\end{aligned}
$$

The second function is just the Euler equation and the traversal condition is $\lambda\left(t_{1}\right)=0$.

\section{References}

[1] A. C. Harberger, "Currency depreciation, income, and the balance of trade," Journal of Political Economy, vol. 58, no. 1, pp. $47-60,1950$.

[2] S. Laursen and L. A. Metzler, "Flexible exchange rates and the theory of employment," The Review of Economics and Statistics, vol. 32, no. 4, p. 281, 1950.

[3] M. Obstfeld, "Aggregate spending and the terms of trade: is there a Harberger-Laursen-Metzler effect," Quarterly Journal of Economics, vol. 97, no. 2, pp. 251-270, 1982.

[4] H. Uzawa, "Time preference, the consumption function, and optimal asset holdings," in Value, Capital and Growth. Honour of Sir John Hicks, J. N. Wolfe, Ed., pp. 485-504, Aldine Publishing Company, Chicago, Ill, USA, 1968.

[5] L. E. O. Svensson and A. Razin, "The terms of trade and the current account: the Harberger-Laursen-Metzler effect," Journal of Political Economy, vol. 91, no. 1, pp. 97-125, 1983.

[6] K. X. D. Huang and Q. Meng, "The Harberger-Laursen-Metzler effect under capital market imperfections," Journal of International Money and Finance, vol. 26, no. 6, pp. 1001-1015, 2007.

[7] P. Sen and S. J. Turnovsky, "Deterioration of the terms of trade and capital accumulation: a re-examination of the LaursenMetzler effect," Journal of International Economics, vol. 26, no. 3-4, pp. 227-250, 1989.

[8] A. Mansoorian, "Habit persistence and the Harberger-LaursenMetzler effect in an infinite horizon model," Journal of International Economics, vol. 34, no. 1-2, pp. 153-166, 1993.

[9] C. Angyridis and A. Mansoorian, "The Harberger-LaursenMetzler effect with with Marshallian preferences," Economics Bulletin, vol. 6, pp. 1-11, 2008.

[10] G. S. Becker and C. B. Mulligan, "The endogenous determination of time preference," Quarterly Journal of Economics, vol. 112, no. 3, pp. 729-758, 1997.
[11] L. T. Gong and H. F. Zou, Growth and Endogenous Cycles in the Ramsey Model with Becker-Mulligan's Time Preference, Working Paper, 2000.

[12] L. T. Gong, "Endogenous time preference, inflation, and capital accumulation," Journal of Economics, vol. 87, no. 3, pp. 241-255, 2006.

[13] M. I. Kamien and N. L. Schwartz, Dynamic Optimization: The Calculus of Variations and Optimal Control in Economics and Management, North-Holland publishing, Amsterdam, Netherlands, 1991.

[14] T. Trimborn, K.-J. Koch, and T. M. Steger, "Multidimensional transitional dynamics: a simple numerical procedure," Macroeconomic Dynamics, vol. 12, no. 3, pp. 301-319, 2008.

[15] L. Serven, "Macroeconomic uncertainty and private investment in developing countries: an empirical investigation," World Bank Policy Research Working Paper, 1998.

[16] T. S. Eicher, S. F. Schubert, and S. J. Turnovsky, "Dynamic effects of terms of trade shocks: the impact on debt and growth," Journal of International Money and Finance, vol. 27, no. 6, pp. 876-896, 2008.

[17] A. Marshall, Principles of Economics, London, UK, 8th edition, 1920.

[18] K.-I. Hirose and S. Ikeda, "Decreasing and increasing marginal impatience and the terms of trade in an interdependent world economy," Journal of Economic Dynamics \& Control, vol. 36, no. 10, pp. 1551-1565, 2012.

[19] O. Cardi, "Another view of the J-curve," Macroeconomic Dynamics, vol. 11, no. 2, pp. 153-174, 2007.

[20] N. Spatafora and A. Warner, "Macroeconomic and sectoral effects of terms-of-trade shocks-the experience of the oilexporting developing countries," IMF Working Papers 99/134, International Monetary Fund, Washington, Wash, USA, 1999.

[21] Y. E. Akbas, M. Senturk, and C. Sancar, "Testing for causality between the foreign direct investment, current account deficit, GDP and total credit: evidence from G7," Panoeconomicus, vol. 60, no. 6, pp. 791-812, 2013.

[22] M. Lanzafame, "Current account sustainability in advanced economies," Journal of International Trade and Economic Development, vol. 23, no. 7, pp. 1000-1017, 2014.

[23] L. Sadiku, M. Fetahi-Vehapi, M. Sadiku, and N. Berisha, "The persistence and determinants of current account deficit of FYROM: an empirical analysis," Procedia Economics and Finance, vol. 33, pp. 90-102, 2015.

[24] A. Chowdhury, "Terms of trade shocks and private savings in the developing countries," Journal of Comparative Economics, vol. 43, no. 4, pp. 1122-1134, 2015.

[25] J. E. Anderson and Y. V. Yotov, “Terms of trade and global efficiency effects of free trade agreements, 1990-2002," Journal of International Economics, vol. 99, pp. 279-298, 2016.

[26] D.-S. Wang and M. Jin, "Nonexistence of Harberger-LaursenMetzler effect with endogenous time preference in an imperfect capital market," Economics Research International, vol. 2015, Article ID 836045, 10 pages, 2015.

[27] K. J. Arrow and M. Kurz, Public Investment, The Rate of Return, and Optimal Fiscal Policy, vol. 218, The Johns Hopkins Press, Baltimore, Md, USA, 1970. 


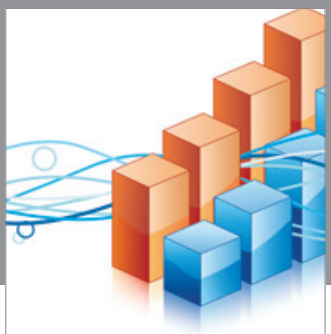

Advances in

Operations Research

vatem alat4

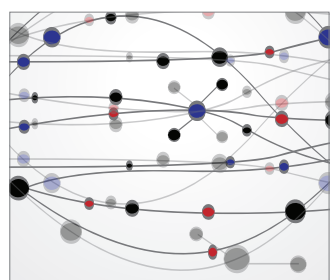

\section{The Scientific} World Journal
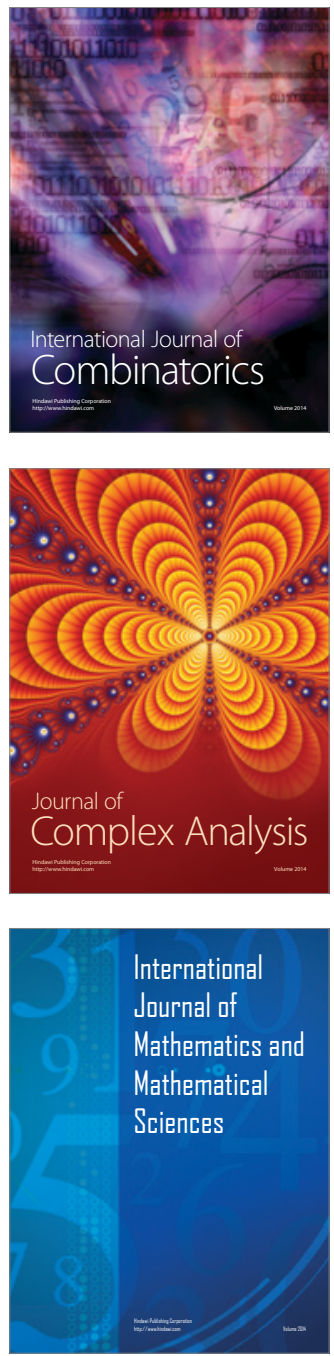
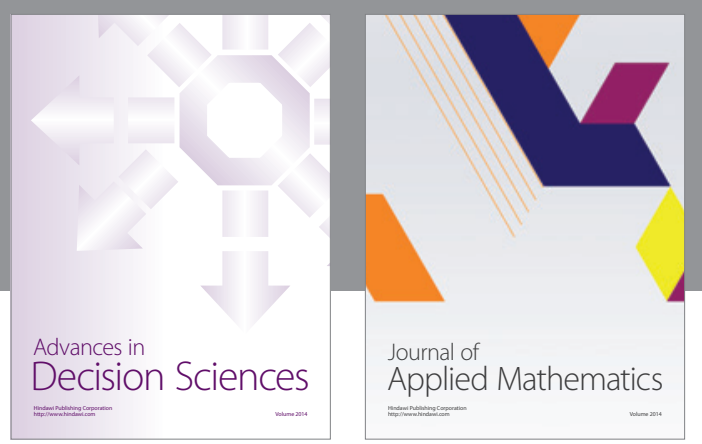

Algebra

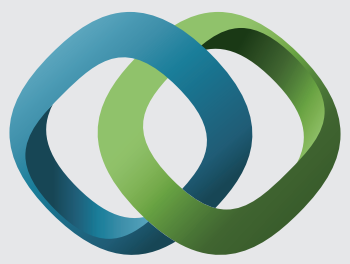

\section{Hindawi}

Submit your manuscripts at

http://www.hindawi.com
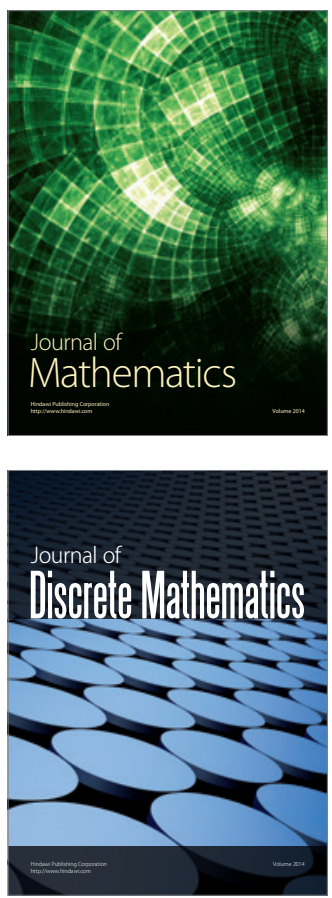

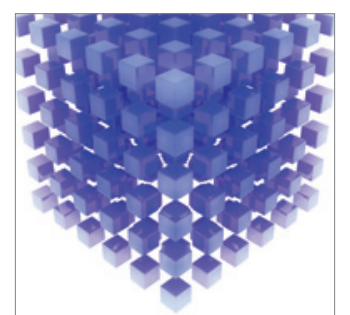

Mathematical Problems in Engineering
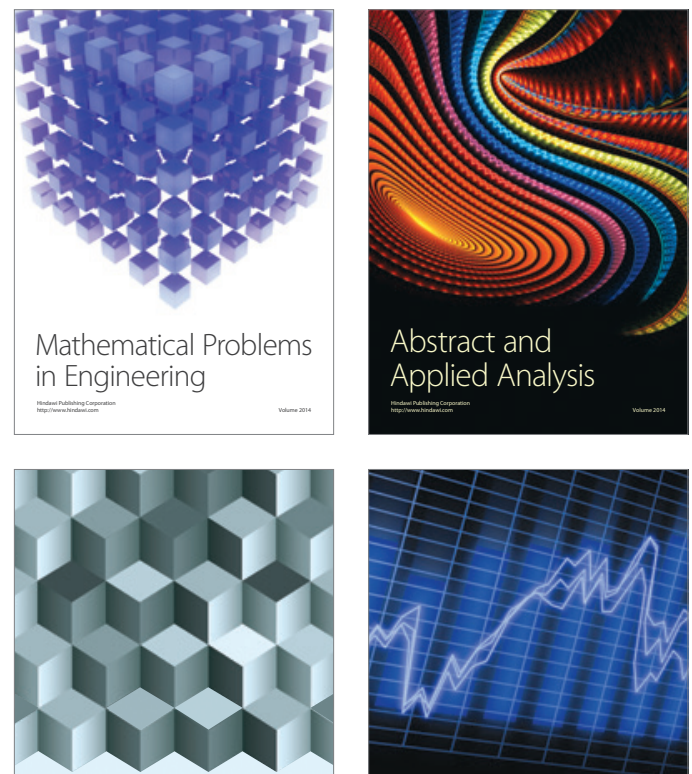

Journal of

Function Spaces

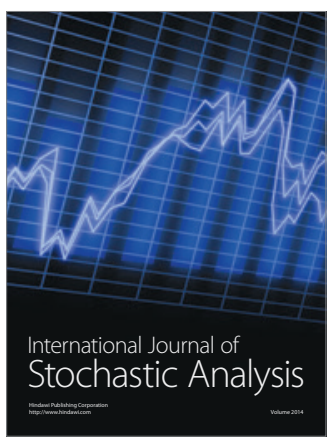

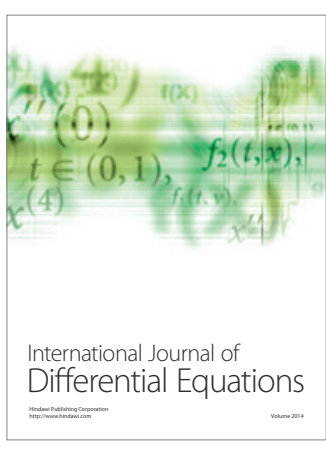
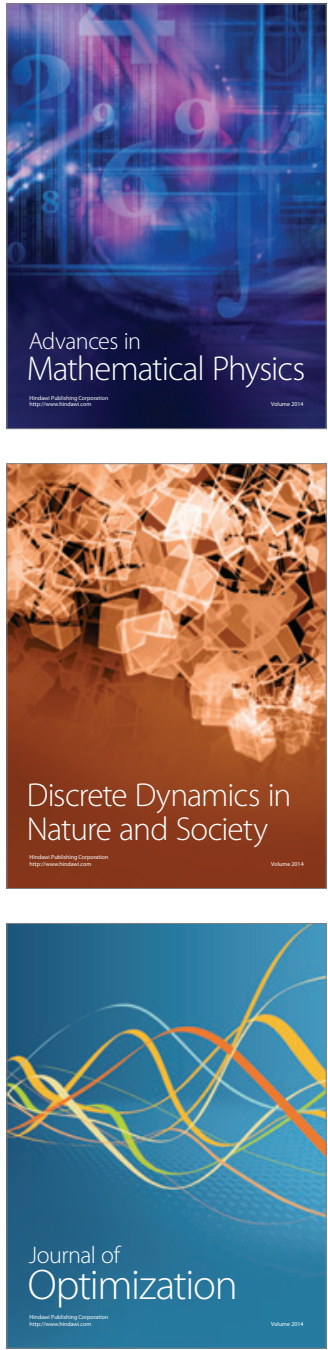